Fecha de recepción: diciembre 2018 Fecha de aceptación: marzo 2019 Versión final: abril 2019

\section{La artesanía salasaca y sus procesos de transculturación estética}

Daniela Larrea Solórzano *

Resumen: El paisaje representado durante diversas etapas de la producción del tapiz salasaca es una muestra de los procesos de transculturación estética que se dieran al interior del mencionado pueblo a partir de los años 1960. Por medio de varias visitas de campo fue posible analizar las historias de vida de los tejedores y artesanos de este grupo indígena. Tomando como base esta información recolectada, en un proceso de observación participante, fue posible elaborar un archivo fotográfico, que articulado con la revisión teórica, dieron paso a la construcción de la trama sobre la cual se fundamenta el análisis propuesto. La iconografía salasaca se constituye en el enlace entre la cultura material e inmaterial de este pueblo, en el que la influencia de las artes plásticas y el diseño transformaron los esquemas de representación gráfica que anteriormente acogían en su interior significantes culturales.

Palabras clave: Transculturación - arte - artesanía - diseño - paisaje - Salasaca.

[Resúmenes en inglés y portugués en la página 174]

${ }^{(*)}$ Diseñadora Gráfica Publicitaria, Magister en Docencia Universitaria, Doctoranda activa del Programa de Doctorado en Diseño - Universidad de Palermo, Argentina. Miembro de la Sección Académica de Artes Plásticas de la Casa de la Cultura Ecuatoriana.

\title{
Introducción
}

Tomando como consideración la noción dominante de la estética occidental, se propone un recorrido gráfico por las transformaciones que se dieran en la iconografía del pueblo Salasaca. Estas modificaciones se ponen de manifiesto sobre el tapiz, objeto artesanal, que se elabora en esta población desde mediados del siglo pasado.

La parroquia Salasaca se encuentra ubicada en la provincia de Tungurahua, en la zona central de los Andes ecuatorianos. Aquí habita el pueblo Kichwa Salasaka, y, aunque se considera que este pueblo se origina fruto de los desplazamientos de mitimaes bolivianos, autores como el historiador Pedro Reino ${ }^{1}$ señalan que la conformación del grupo indígena guarda cinco componentes interétnicos. Según describe Reino (2017) el pueblo salasaca tuvo su origen en las mezclas de los antiguos habitantes de las zonas de Perú y de Bolivia, así como también de dos sectores dentro de la actual delimitación del territorio ecuatoriano. 
Lo que resulta fascinante en el proceso de conformación del pueblo Salasaca, es que precisamente, las culturas Precolombinas, que son la base para su formación como pueblo autónomo, contaban entre sus características el ser diestros en el arte del tejido, condición que sería trasladada de generación en generación y cuya práctica se mantiene.

Los salasacas, que hasta los años 70 del siglo pasado, aún conservaban la idea de ser un pueblo hermético, impedían el ingreso a su comunidad de habitantes provenientes de otros sectores (sobre todo mestizos). Sin embargo, podían desarrollar su vida de modo autónomo, pues tenían la posibilidad de producir todo lo necesario para su actividad diaria. La elaboración de su propia indumentaria y de los objetos utilitarios, además con fines rituales, es una característica que se mantiene hasta la actualidad. Ulf Scheller (1972), quien desarrollaría uno de los primeros trabajos de investigación y registro fotográfico sobre este grupo indígena, llegaría a señalar que su modo de vida y "su aversión a toda forma de autoridad e influencia externa, los lleva a ser un ejemplo de socialismo" (Scheller, 1972, p.12). En el texto El mundo de los salasacas Scheller destaca que sería precisamente la práctica del tejido, sobre todo, la elaboración del tapiz (que se diera en el pueblo desde finales de los años 1950) y su comercialización, el hecho que les permitiría romper barreras y dar origen al intercambio de los pobladores salasacas con otras comunidades.

La práctica del tejido, dentro de este pueblo, es uno de sus rasgos culturales más importantes, pues no solo conservan la experiencia de la elaboración de su propia indumentaria, incluyendo la confección de la vestimenta de diario, la ritual y la festiva. Además, dentro de esta actividad productiva es posible evidenciar prácticas culturales e incluso ancestrales, tales como la preparación de los materiales, fundamentalmente de su materia prima, la lana. A pesar de que las prácticas productivas han ido variando por diversos motivos, sobre todo asociados a la reducción de los tiempos de trabajo, aún dentro de la comunidad existen familias que recurren al tratamiento y tintura natural de la lana. El hilado sigue siendo una actividad sobre todo femenina y el tejido mayormente es realizado por hombres. En las condiciones actuales, los tejedores escasamente se dedican solo a esta actividad debido a que los ingresos que se obtienen por el trabajo artesanal disminuyeron considerablemente a partir del año 2000, cuando Ecuador dolarizó su economía.

El modo en el cual es elaborado el tapiz salasaca obedece a la introducción de una nueva forma de tejido en el pueblo bajo el conocimiento del uso del telar europeo, diferente al telar de cintura que tradicionalmente se usaba, pero que ahora se encuentra restringido solo para la elaboración de las fajas. La introducción de esta nueva herramienta y por ende la producción de nuevas piezas (específicamente el tapiz) pone de manifiesto uno de los procesos de transculturación que se viviera al interior de este pueblo.

Ticio Escobar (2012) considera que el término transculturación permite complejizar la teoría del conflicto cultural, pues se define como un proceso que implica parcialmente tanto adquisiciones como pérdidas, que en palabras de Adriana Valdés representa "la creación de nuevos fenómenos culturales" (Valdés 1990, en Escobar 2012, p. 51).

En el presente análisis se asume como objeto de estudio el tapiz salasaca, que es una pieza hecha por este pueblo indígena, cuya elaboración fuera dejada de lado por muchos años. Su práctica se retomaría mucho tiempo después bajo influencias externas al propio pueblo. El tapiz es un objeto que en sí mismo no conserva su núcleo simbólico (que sí existiera 
en su producción original para las culturas Precolombinas). Sin embargo, las modificaciones constantes dentro de su gráfica posibilitan que en algunos casos se reconozcan elementos iconográficos que conservan su simbología ancestral, mientras que en otros no existe ningún elemento asociado directamente a las concepciones cosmológicas o míticas del pueblo. Por el contrario, algunas de estas representaciones están más vinculadas a características estilísticas occidentales.

Es entonces, que por medio de los elementos gráficos proyectados en este soporte, se puede definir un registro de los procesos de transculturación estética que se dieran en el citado pueblo. En este caso, tomando como ejemplo las formas en que el paisaje se representa, y cómo este elemento se constituye en una muestra de la unificación entre los campos del arte, la artesanía y el diseño dentro del trabajo realizado por estos artistas del tejido. El proceso productivo de este elemento, que sirve como corpus de estudio, permite reconocer los fenómenos de permeabilidad cultural que surgieran al interior del pueblo salasaca, a partir de los años 60. De este modo, se analiza el tránsito conceptual desde el arte culto al arte de los otros, que se manifiesta en la práctica cultural salasaca como resultado de injerencias de diversos sectores (con diversas corrientes de pensamiento y líneas de acción), pero todas asociadas a la práctica artesanal.

Lévi-Strauss (1971) decía que se puede concebir al arte como un conjunto de sistemas significativos pero que se queda siempre a medias entre el lenguaje y el objeto. Desglosar entonces los significados de formas, colores y texturas así como los materiales representativos de un pueblo permite concebir con mayor claridad sus formas de pensamiento y las variantes constantes que se dan dentro de sus prácticas culturales.

\section{La estética y la morfología de la artesanía salasaca}

Cuando se menciona el término estética, es aún común, referenciar de forma inmediata, la concepción que alrededor de 1750 Baumgarten estableciera sobre esta disciplina a través de la cual se hacía posible el "estudio filosófico y científico del arte y de lo bello". El objeto de estudio de la estética, desde esta concepción, estaba guiado por la definición de las categorías estéticas, que durante los siglos XVIII y XIX contenían las adjetivaciones relacionadas con el arte que permitían descomponer el concepto de lo bello en una obra. La conceptualización sobre la estética por tanto, estaría asociada de forma directa a la producción artística (entendiéndose de este modo, el arte producido sobre todo en occidente). Según Souriau (2010) la estética es la encargada del estudio de las categorías estéticas, que se hacen presentes como observables, por medio de su representación, en las obras de arte. Bajo el uso de estas categorías estéticas se originan nuevos saberes por los cuales se puede comprender a la propia creación artística y al artista. Al mismo tiempo, estas categorías estéticas posibilitan el estudio de las formas contenidas en la obra, permiten el análisis de las sensaciones que provocan las obras y brindan facilidad para comprender de las relaciones entre esas obras y la sociedad.

Aunque esta definición de estética nace desde una postura occidental y se asocia también a la concepción sobre el arte que contiene la misma forma de pensamiento (que se forta- 
lece dentro del periodo renacentista), los estudiosos dentro de este campo suelen hacer excepciones selectivas cuando aplican estos conceptos. De tal modo que nadie niega la existencia de una estética greco-romana, o egipcia, del mismo modo suelen considerar pertinente hablar de las estéticas amerindias o precolombinas. No obstante, bajo el término estética casi siempre queda excluida la referencia hacia los pueblos indígenas o grupos étnicos situados fuera de las capitales del arte.

Una de las razones fundamentales cursa por el hecho de que la estética, desde la mirada occidental, propicia la unicidad del genio artístico e intenta (o al menos intentó hasta el siglo XIX) mantener separada la forma de la función, favoreciendo en el análisis de las obras las categorías formales, pues esta debía ser su única intención (Tatarkiewicz, 2001). Sin embargo, en el caso de las producciones artísticas creadas por los pueblos indígenas fuera de estos patrones, cada pieza producida combina forma y función, e incluso acarrea en sí significantes simbólicos (Sharman, 1997; Montani, 2008; Escobar, 2012, 2014; Matarrese, 2013; Barroso, 2014).

Para Sharman la expresión estética conlleva la "recreación humana de la experiencia a través de la cual se reconstituyen y/o transforman los valores unidos mediante la percepción estética" (1997, p.183)². Por lo tanto, la expresión estética es el paraguas que reviste la totalidad del proceso creativo, de tal modo que involucra no solo la producción material, sino además el contexto cultural y el proceso productivo.

No obstante, ante el desajuste de estas otras producciones generadas frente al concepto dominante de estética, las obras desarrolladas por estos otros grupos no son tratadas como producciones artísticas. En el mejor de los casos llegan a ser denominadas artesanías, llevando consigo aún la designación peyorativa de la artesanía frente al arte.

De acuerdo al pensamiento de Ticio Escobar este fenómeno se generó por la constitución del mito del arte que se definiría como uno de los grandes relatos de la modernidad, y, según el cual, las oposiciones conceptuales entre forma y contenido, o entre estético y artístico, forman un modelo cultural que dice autorrepresentar a todos. Empero, las transformaciones conceptuales que se fueran gestando (muchas de ellas a propósito de las vanguardias artísticas) en el siglo XX sobre las ideas de estética y de arte, han separado, el vínculo fiel que antes existía entre estos dos componentes. Por un lado "lo estético involucra el ámbito de lo bello, la búsqueda de la armonía formal y la síntesis de lo múltiple en un conjunto ordenado, mientras que lo artístico se abre a la posibilidad de intensificar la experiencia de lo real, movilizar el sentido" (Escobar, 2014, p.44).

Bajo este modelo de pensamiento, el crítico de arte paraguayo propone un concepto de arte indígena al cual describe como la producción de objetos en los que significantes y significados muy variados se mezclan, haciendo imposible que exista una separación entre la utilidad y la belleza en dichas construcciones. La admisión de la existencia de esta forma diferente de arte puede ayudar con la eliminación de las posturas artísticas discriminatorias que se han forjado desde el arte occidental. Al comprender la valía de los registros simbólicos contenidos en los elementos físicos se favorece el acceso a "mecanismos poéticos, retóricos y estilísticos fundamentales para complejizar la comprensión de las culturas étnicas (...) ignorados por los conceptos de cultura material, de artesanía o de folklore" (Escobar, 2012, p.33). 
Al reconocer entonces, la existencia de un arte producido por los otros ${ }^{3}$ se acepta también la existencia de una estética generada por los otros. Matarrese en su abordaje sobre "las valoraciones estéticas de los pilagá con respecto a sus producciones cesteras" (2013, p.125) enfatiza que el análisis de la producción artesanal del pueblo pilagá se realiza desde la concepción de sus artesanías como expresiones estéticas y no como objetos aislados. Esta visión posibilita el estudio de la producción en un contexto que rebasa los límites culturales, en la que sin embargo, las concepciones estéticas constituyen factores para la propia definición identitaria del pueblo.

Entonces, en función de estos enunciaciones conceptuales, ¿cómo puede definirse la estética salasaca?, si en el caso de la producción específica del tapiz, la iconografía en algunos momentos obedece a connotaciones simbólicas, pero en otras ocasiones no, y sin embargo, este producto artesanal sigue siendo reconocido como una de las principales muestras públicas de su cultura.

Al respecto, conviene, en primer lugar establecer, que los motivos considerados por el pueblo como autóctonos se encuentran sobre todo tejidos en las chumbis o fajas ${ }^{4}$ que usan como parte de su vestimenta; los pobladores salasacas consideran también como sus motivos originarios, aquellos que se encuentran representados en los bordados de pañuelos y pantalones masculinos o en las camisas de las novias. Además, en estas representaciones bordadas, no solo se encuentran presentes las gráficas geométricas que se ponen de manifiesto sobre las chumbis, sino que adicionalmente se incorporan formas de representación de las costumbres - principalmente de corte religioso- que asumieran los salasacas posteriormente a la conquista española. Estos motivos presentes en los bordados representan otra de las etapas de transculturación que se diera al interior del pueblo salasaca, que sin embargo, se excluyen de tratamiento en el presente análisis.

Se cita como referencia estos antecedentes en función de establecer que los motivos presentes en las fajas salasacas se constituirían en el registro de partida para la definición estilística y estética de este pueblo. Esta definición estética, fruto de los procesos de intercambio cultural que se han suscitado en el transcurso del tiempo, ha ido variando como consecuencia no solo de fenómenos socio-culturales, sino también políticos. Varios procesos políticos (que se dieran en Ecuador) generaron conflictos económicos que desembocaron en algunos procesos migratorios, que también influenciaron la transformación de la gráfica salasaca. Aunque, en este caso específico, se centra la atención en los intercambios que se dieron con personajes y organismos asociados a los campos del arte y del diseño, y que asimismo propiciaron transformaciones en la iconografía salasaca.

\section{El paisaje representado: la unificación del arte, la artesanía y el diseño en el pueblo Salasaca a través de un motivo específico}

El paisaje, al que en este caso se refiere el artículo, lo constituye un determinado tipo de obra que representa la configuración física de una región geográfica. Como lo describe Souriau (2010), la forma en que se expresa el paisaje en una obra de arte se dirige hacia los mismos sentidos que el propio paisaje, por lo que entabla una idea análoga, que sin 
embargo, no es la propia identidad del paisaje, "pues existe siempre una transposición que implica unas elecciones del artista. La pintura presenta una obra en dos dimensiones donde la profundidad es ficticia" ( $p$.861). Según la autora, el paisajista contempla y reconoce la existencia de un mundo exterior; lo escucha, lo observa y encuentra en el paisaje interés hacia el propio yo. De este modo, así como el paisaje puede evocar atmósferas reales, y a través de ella establecer metáforas o alegorías, también puede representar ideas abstractas, ficticias e incluso mágicas. A la par "un paisaje puede tener, en sí mismo, una forma determinada, entonces la acción del artista, para componerlo, residirá en la elección del punto de vista" (Souriau, 2010, p.861).

En Ecuador, en el marco de una corriente de arte naif, marcada por aires indigenistas, dados los fuertes contraste entre el color y la forma que conjugan las obras, se reconocieron algunos artistas, entre ellos Endara Crow, Salvador Bacón o Whitman Gualsaquí. Sin embargo, estas formas de expresión del arte naif que están también presentes en el trabajo de pintores indígenas, como aquellos artistas de la comunidad de Tigua, dejan de ser consideradas dentro de la totalidad de la producción naif. En estos casos se usa la traducción al español de este término francés para hablar de ellos como pintores ingenuos. En este sentido y desde una opinión personal, dicha diferenciación se realiza no con la intención de resaltar su trabajo sino, más bien, como una manera de diferenciarlos ante los pintores academicistas y no indígenas.

Esta forma de expresión ingenua, en el territorio ecuatoriano, puede ser observada no solo en la pintura de los artesanos de Tigua, sino además en los tapices realizados en Salasaca y Otavalo. Y si bien (como se ejemplifica en las figuras 3 y 4), en el caso del tapiz salasaca son evidentes estas formas asociadas al costumbrismo, se puede establecer, que este modo de representación no es el originario del pueblo Salasaca.

Como se señaló en el punto anterior, los motivos más antiguos (y considerados autóctonos) dentro de la producción salasaca pueden observarse en los tejidos de las fajas. Así, puede comprenderse que sus representaciones originales guardan una base geométrica y sus formas son estilizadas abstracciones. La presencia de altos contrastes (positivo y negativo) es fundamental en su construcción, pues deviene de conceptos que obedecen a la cosmovisión andina. El concepto de Ayllu, considerado como la unidad indivisible señalada en la sociedad andina, se hace presente dentro de estas representaciones, llevando consigo, además, componentes simbólicos. El concepto de Ayllu, se asocia con el prójimo, el miembro de la comunidad, que se solidifica por el trabajo conjunto. Es por esto que según Milla Villena (1992) el Ayllu conformado por los opuestos: Hanan (alto) y Urin (bajo), define un tercer elemento denominado Sayas que es la forma de expresar la unidad. En las figuras 1 y 2 es posible, en primer lugar, identificar los conceptos aquí descritos.

Como puede observarse en las figuras siguientes, si bien en estas no se encuentra representado de modo figurativo un paisaje, si es posible aquí reconocer la presencia de elementos antropomorfos y zoomorfos, que generalmente son parte de la estructura del paisaje. En estas gráficas prima la simetría, el contraste entre positivos y negativos, la abstracción geométrica, así como la estructura cuadrangular base, que rota y se desplaza para definir las formas. En las fajas se encuentran también otro tipo de representaciones abstractas que están vinculadas con la naturaleza. Las hileras dispuestas a los lados de las figuras centra- 
les a modo de zig-zag, son una representación general de los quingos ${ }^{5}$ que simbolizan las acequias, y es uno de los motivos con mayor uso dentro de las representaciones salasacas. Los quingos se conjugan con representaciones de la planta de frutilla, estos dos elementos son distinguibles en las fajas por la variedad de su color.
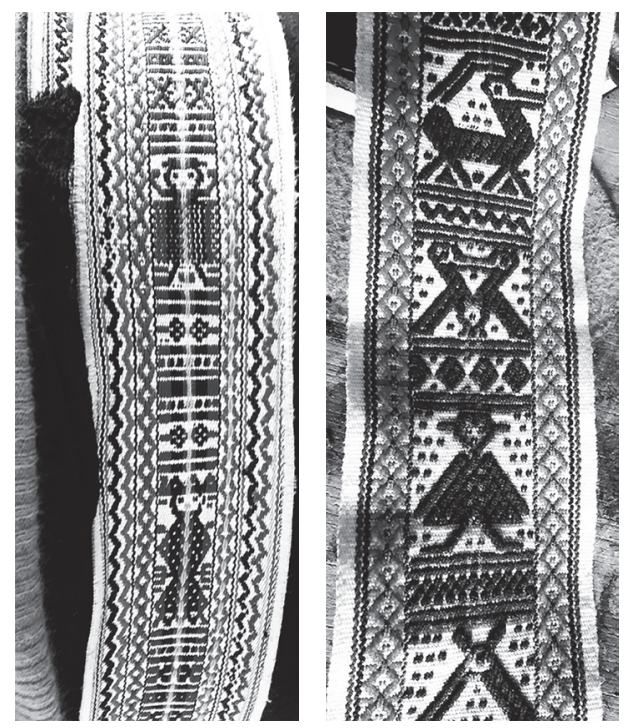

Figuras 1 y 2. Muestras de fajas salasacas. Fuente. Foto de la autora.

Estos modos de representación contrastan de manera muy fuerte con las formas en las que se expresa tempranamente el paisaje sobre el tapiz. En las figuras 3 y 4 se hallan dos ejemplos de cómo es representado el paisaje por los tejedores de esta zona (las imágenes corresponden a elaboraciones de los años 70 y 90 del pasado siglo). En las dos figuras es evidente que la construcción geométrica no es la base de organización de los elementos. Las figuras zoomorfas y antropomorfas aquí tejidas no se acercan a la conformación dispuesta en las fajas, es decir, los motivos originales y sus formas de representación no son acogidas para su expresión en el tapiz. Si bien en estas dos imágenes (fig. 3 y 4) se rememora al paisaje andino (asociado a las montañas y la presencia del volcán Tungurahua cercano a la parroquia Salasaca), la morfología de las viviendas no se compadece con la tipología de las construcciones salasacas tradicionales. Más aún, la presencia de una iglesia, permite asimismo reconocer el periodo en el cual la obra fue realizada, considerando además la incorporación de las tejas en el segundo trabajo aquí analizado. En la figura 4 las sombras dispuestas, tanto en las ventanas de las casas como en el suelo, incorporan a la representación del paisaje la categoría del volumen que antes era ausente en la expresión salasaca. 

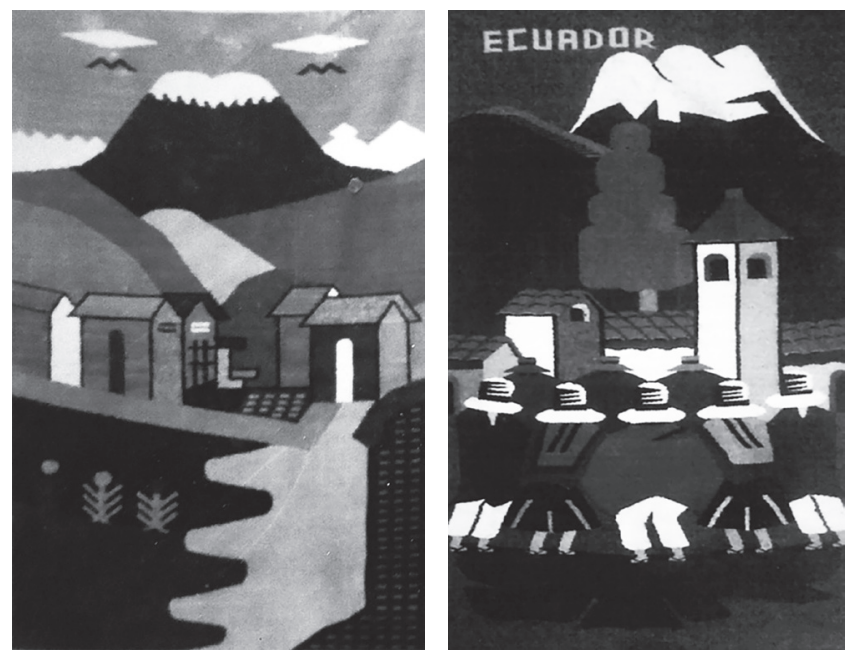

Fig. 3 y 4. Representaciones del paisaje andino presentes en el tapiz salasaca, el primer trabajo fue realizado en los años 1970 y el segundo se elabora desde la década de 1990. Fuentes: La primera imagen es una recopilación de la autora sobre el trabajo efectuado por el tejedor Juan Masaquiza (chuper) y la segunda fue recolectada del archivo del taller Curindi.

En las figuras 3 y 4 hay variantes notorias entre el modo de definir los elementos fitomorfos. Mientras que las matas dispuestas en la parte inferior del paisaje de la figura 3 son más cercanas a las formas utilizadas en las fajas, en la figura 4 la presencia de un árbol de configuración más simple pero orgánica se separa más aun de los motivos ancestrales. No obstante, en los dos casos citados, se puede identificar una forma de expresión ingenua que nacería, obviamente, por el intercambio con otros sectores. Durante la década de los años 60 los artesanos salasacas participaron en diversos talleres juntos a pintores que desarrollaban su obra bajo el paraguas del movimiento indigenista, estos vínculos fueron posibles por medio del trabajo de la Casa de la Cultura Ecuatoriana. Posteriormente, en los años 70, los artesanos salasacas empezaron a expandir la venta de sus tapices y a llevar su obra a las ferias artesanales de otras provincias. Uno de estos espacios que recorrieron fue la feria artesanal de Pujilí, donde fue posible el conocimiento del trabajo de los pintores ingenuos de Tigua. Este proceso de reciprocidad cultural puede observarse en las representaciones humanas de la figura 4 , donde la vestimenta de los personajes permite comprender la unidad existente entre diversos pueblos.

La habilidad de los tejedores salasacas hizo que rápidamente se extendiera, dentro del Ecuador, el reconocimiento hacia el trabajo artesanal que se hacía en este sector, lo cual llamó la atención de artistas y galerías de arte que empezaron a comercializar su obra en espacios fuera de la comunidad, llegando incluso a exportar tapices en gran cantidad du- 
rante los años 1970 y 1980 especialmente a Estados Unidos. El prestigio que poco a poco fue ganando el tapiz salasaca hizo que algunos artistas plásticos decidieran trabajar con ellos su propia obra. El artista Peter Mussfeldt, sorprendido por la habilidad y la forma en que se desarrollaba el tapiz decidió que una parte de su obra de pintura y grabado fuera también trasladada a este soporte. El contacto directo con los artesanos hizo que en este intercambio no solo Mussfeldt transformara su obra, sino que además los tejedores salasacas acogieran algunos de los motivos y formas que el citado artista ponía de manifiesto a través de su trabajo.

La figura 5 es una muestra de esta nueva etapa de transculturación estética que se diera en la obra salasaca. El modo en que durante este periodo se muestra el paisaje desde la visión salasaca estuvo influenciado de forma directa por la obra de Peter Mussfeldt. Existen variantes en la paleta cromática, que se presenta llena de contrastes vivos, además, las formas se simplifican al máximo y se observa la presencia de elementos asociados al diseño. La gradación de formas y colores, la repetición de planos, el uso de figuras básicas, no solo permiten identificar la época en la cual esta producción textil se asocia a la obra de Mussfeldt, también, durante este período de tiempo, es más notoria la formación y la práctica de diseñado desempeñada por el artista alemán - ecuatoriano.

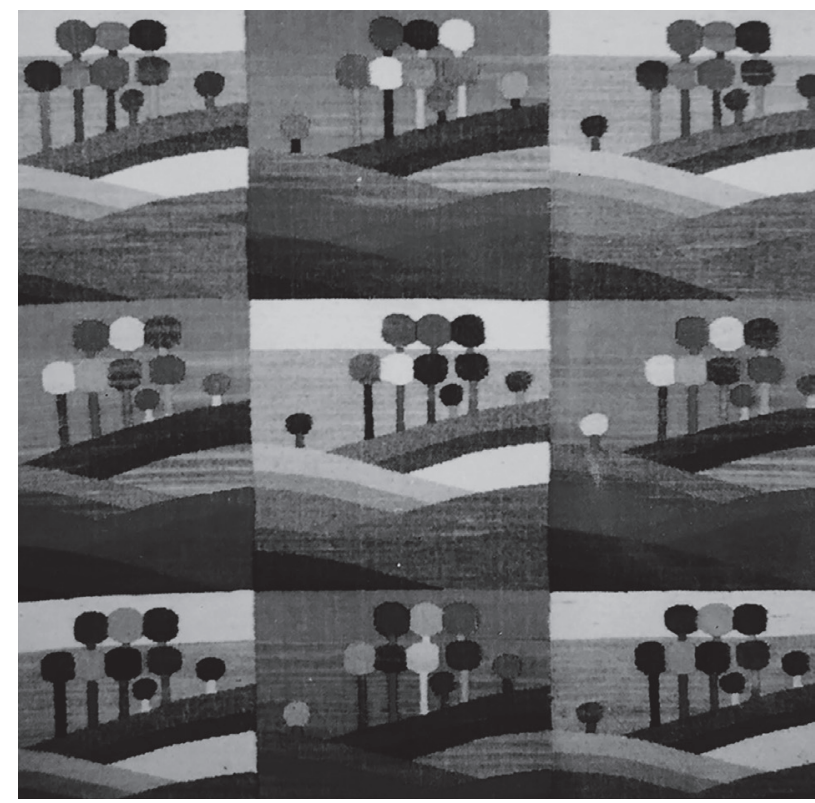

Figuras 5. Paisaje salasaca elaborado bajo la influencia estilística del artista Peter Mussfeldt. Fuente: Foto efectuada por la autora. 
Por tanto, la nueva estructura proyectada del paisaje salasaca rompe con la tradición de formas vinculadas hacia el indigenismo y es una muestra de la presencia de corrientes asociadas al modernismo dentro del tapiz de este sector. Cada una de las nueve secciones del paisaje representado en la figura 5 es por sí misma ejemplo de una novel postura estilística dentro de este grupo de artesanos. Adicionalmente, la obra en su conjunto, unificando los nueve módulos que la conforman, más el contraste cromático que se selecciona para su elaboración, evoca un trabajo de la época del Pop Art. La diferencia radica en que en este caso el soporte no es un lienzo y la pintura se forma por el uso de lanas de colores, entre las cuales, aquellas tinturadas de forma natural ya no tienen cabida. Los colores brillantes y de alto contraste (que incluyen variantes de anaranjados, fucsias, azules y verdes) no pueden ser obtenidos usando plantas e insectos para su definición cromática y por esta razón las lanas tinturadas de forma industrial son necesarias para este tipo de demostraciones artísticas.

La presencia de estos elementos estilísticos, asociados a una de las vanguardias artísticas del siglo XX, es una muestra más de cómo la transculturación permitió acoger en un primer momento casi la totalidad de la influencia de esta corriente. Posteriormente, este conocimiento sería deconstruido y re-estructurado para dar origen a otra propuesta estilística que se originan entre los tejedores salasacas. Este modo de representación pone en evidencia cómo las diversas variantes estilísticas de las artes plásticas pueden ser incorporadas en el trabajo de este pueblo indígena. De tal modo que, con el uso de estos elementos (antes ajenos a su práctica artística), se configura una nueva forma que permite dar a conocer su pensamiento y su cosmovisión.

La siguiente figura analizada es un ejemplo de cómo el proceso de asimilación de nuevos conocimiento, fruto de los intercambios culturales permanentes, permitió trasformaciones en la morfología de la artesanía salasaca. Al mismo tiempo, estas búsquedas de elementos externos a su convivir diario, para la representación, no se apartan del modo de pensamiento del pueblo, y ante el uso de estos nuevos recursos se busca resignificar elementos culturales propios.

Diversos autores como Juan Acha (1981, 1993) o Néstor García Canclini (2005) consideran que las construcciones objetuales de un pueblo pueden trasformar su significación en función de los nuevos usos o las reapropiaciones sociales que los objetos producidos por los grupos indígenas puedan generar. Esta trasformación de la significación inicial se desarrolla en medio de un proceso constante de producción, circulación y consumo de bienes culturales, a través de interrelaciones que permiten asimilar, en la práctica, el ser intercultural.

Los procesos socio-culturales de los que fuera partícipe el pueblo salasaca han llevado consigo diversos significados. Éstos han sido recibidos y recodificados por este pueblo, siendo notorio cuando en cada una de estas etapas la fuerza mayor para modificar las significaciones iniciales ha estado dentro o fuera de la propia comunidad. La transformación de estos significantes culturales se acrecentó a partir de los años 1980, cuando los constantes intercambios de forma directa junto a artistas o galerías les permitieron conocer nuevos recursos estilísticos. Adicionalmente, los procesos migratorios del pueblo y el fenómeno de globalización, que expandió las formas de comunicación, establecieron nuevas relaciones interculturales. En el marco de estos procesos se hace necesario reconocer el fondo socio-histórico y simbólico en el que se ejecutaron estas nuevas maneras de expresión sobre el tapiz a fin de comprender integralmente estos cambios. 


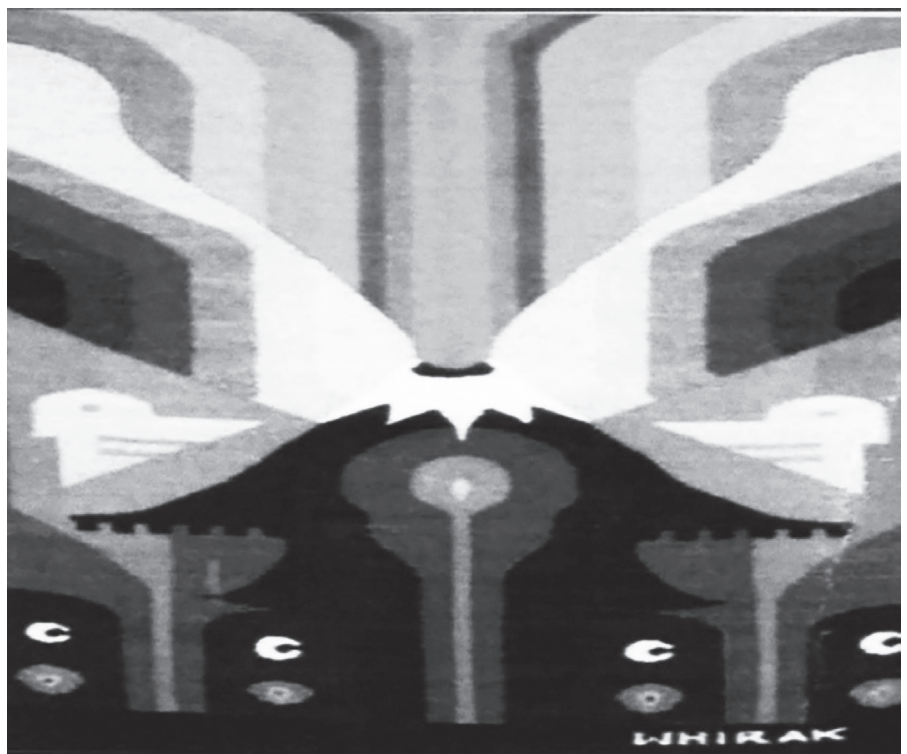

Figuras 6. Paisaje. Obra elaborada por el artista salasaca Whirak - Franklin Caballero. Fuente: Foto de la autora

En la figura 6, el artista salasaca Whirak ${ }^{6}$ ha elaborado un paisaje que tiene como elemento principal, una vez más, el volcán Tungurahua, de cuyo centro emana un río, acompañado por aves más estilizadas y símbolos asociados al sol y la luna en la parte inferior. En esta obra, que se configura bajo un eje simétrico, es posible reconocer la apropiación de formas de diseño como las expuestas en la figura $\mathrm{N}^{\circ} 5$. No obstante, en este trabajo, la gráfica modernista, que puede incluso ser tratada como ejemplo del movimiento pop, es recuperada para la exposición de expresiones andinas, mediante el uso de colores vibrantes que son acogidos para reforzar precisamente la cercanía de este pueblo con la naturaleza.

Por medio de esta obra (fig.6) elaborada ya en los años dos mil, se pone de manifiesto la necesidad de desentrañar este nuevo sistema de representación, en el que existen formas de interacción, pero también de rechazo, que nos permiten comprender los nuevos contextos en los que ahora se teje el tapiz.

\section{Conclusiones}

En esta secuencia gráfica se realizó un paneo general de la cultura visual salasaca que actualmente acoge elementos no solo autóctonos en su modo de expresión. Adicionalmente, como señala García Canclini (1987a), forja un escenario que abarca imágenes y diseños 
que son parte de la organización simbólica específica de cada sociedad. En este contexto las artesanías, el arte, el diseño, la arquitectura, se cruzan y se interpretan. Y precisamente esta nueva cultura visual tiene su origen en la ruptura de aquellos límites imaginarios entre el arte, la artesanía e incluso el diseño. Límites que poco a poco se han ido permeando, de tal modo que, así como los artistas que son parte de la elite han recurrido a las obras y al trabajo de los artistas salasacas, también estos últimos han mirado hacia las vanguardias artísticas para incorporarlas a sus modos de expresión.

Este fenómeno, empero, no trata solamente la ampliación de los repertorios en las prácticas artísticas, sino que adicionalmente abre el debate sobre la inserción de los territorios considerados exclusivos del arte, pero también de la propia simbología existente dentro del pueblo salasaca. Tal como lo establece García Canclini (1987b) las prácticas culturales y artísticas actuales que se desarrollan al interior de los grupos indígenas ya no son estrictamente tradicionales. En la actualidad, sus conocimientos ya no se transmiten completamente de una generación a otra, ni circulan en forma oral de persona a persona, y, los artistas y sus prácticas ya no son anónimos. Para Guss (1989), el proceso de trasformación continua de estos símbolos permite que una cultura se perpetué bajo la capacidad de procesar las nuevas ideas que acoge. Algo que Sahlins definiría como la "revolución funcional de los signos" (en Sharman, 1997), permitiendo la incorporación de otros elementos en la concepción general que antes guardaban y que comunican una forma de expresión estética específica para un sector.

Las transformaciones socio culturales que se dieran en el pueblo Salasaca y también en varios puntos de Latinoamérica, demandan la definición de una cultura estética en la que se consideren los procesos pasados y presentes, que relacione el vínculo entre las culturas estéticas hegemónicas y populares que conviven (en este caso dentro del territorio nombrado), y que reconozca las formas en las cuales las apropiaciones, las resignificaciones e incluso los rechazos, son muestra de la transculturación que viviera cada pueblo, y que en el caso de Salasaca se pone de manifiesto a través de su práctica artesanal.

\section{Notas}

1. Los datos proporcionados por este autor, a más de los registros existentes en sus publicaciones, han sido recolectados en conversaciones y entrevistas efectuadas durante la investigación.

2. Traducción personal de la cita de Sharman.

3. Otros, otredad; como lo señala Fandiño (2014, p.50), "aquellos que consideramos como los "otros", han sido nombrados y definidos con categorías que tratan de mostrar que sus cualidades están por debajo de aquellas que han sido catalogadas como "normales". El otro, visto desde la mismidad es "nombrado" como portador de algún prefijo, por ejemplo: a-normal, a-dolescente, anti-social, in-válido, dis-capacitado, sub-alterno, subversivo, sub-desarrollado, entre tantos otros".

4. La morfología y la iconografía presente en las fajas también se ha modificado en función del vínculo con la moda. 
5. Los quingos tejidos en las fajas hacen referencia a las acequias construidas en la zona. Según lo señala Hans Hoffmeyer (1985), es posible que la importancia del uso de este símbolo se deba a la configuración geográfica donde habita el pueblo Salasaca, que en su mayoría, corresponde a un territorio árido donde escaseaba el agua y los quingos cumplían un papel fundamental para la sobrevivencia del pueblo.

6. El artista tejedor salasaca Franklin Caballero personalmente describiría a la investigadora las significaciones expresadas a través de su trabajo.

\section{Lista de Referencias bibliográficas}

Acha, J. (1981). Arte y sociedad Latinoamericana: El producto artístico y su estructura. (1 ${ }^{\mathrm{a}}$ ed.). México. Fondo de Cultura Económica.

Acha, J. (1993). Las culturas estéticas de América Latina (Reflexiones). México. Universidad Nacional Autónoma de México.

Barroso, N. (1999). Diseño y artesanía: límites de intervención. Artículo. Recuperado en: http://artesaniasnamaste.blogspot.com/2016/03/diseno-y-artesania-limites-de.html

Escobar, T. (2012). La belleza de los otros. (2 ${ }^{\text {a }}$ ed.). La Habana. Fondo Editorial Casa de las Américas.

Escobar, T. (2014). El mito del arte y el mito del pueblo: Cuestiones sobre arte popular (1 ${ }^{\mathrm{a}}$ ed.) Buenos Aires. Ariel.

Fandiño, Y. (2014). "La otredad y la discriminación de géneros. En Advocatus. Volumen 11 no. 23: 49 - 57. Barranquilla. Universidad Libre Seccional.

García Canclini, N. (1987)a. Narciso sin espejos. La cultura visual después de la muerte del arte culto y del popular. Ponencia. En Conferencia Internacional de CLASO: "Identidad latinoamericana, modernidad y posmodernidad". Buenos Aires.

García Canclini, N.(1987)b. "Ni folklórico ni masivo ¿qué es lo popular?" En Diálogos de la comunicación, ISSN 1813-9248, No. 17.

García Canclini, N. (2005). Diferentes, desiguales o desconectados. Barcelona. Gedisa.

Guss, D. (1989). To Weave and Sing: Art, Symbol, and Narrative in the South American Rain Forest. Berkeley. University of California Press.

Hoffmeyer, H. (1985). Diseños Salasacas. PNUD-FAO-ECU 79-007. Revista Cultura 1985 n.21a. Banco Central del Ecuador.

Matarrese, M. (2013). "Antropología y Estética: el caso de la cestería pilagá (Gran Chaco, Argentina)". En PROA - revista de antropologia e arte.

Milla, C. (1992). Génesis de la Cultura Andina. Lima. Fondo Editorial C.A.P.

Montani, R. (2008). "La etnicidad de las cosas entre los wichís del Gran Chaco (provincia de Salta, Argentina)”. En íNDlANA 25 (2008) 117-142. Berlín.

Pérez, D. (2010). "El Diseño como Apoyo a la Generación de Productos Regionales para Competir en el Mercado". En Temas de Ciencia y Tecnología vol. 14 número 40 enero abril 2010 pp $31-36$.

Scheller, U. (1972). El Mundo de Los Salasacas. Guayaquil. Fundación Antropológica Ecuatoriana. 
Sharman, R. (1997). “The anthropology of aesthetics: a cross-cultural approach”. En Journal of the anthropological society of Oxford, JASO 28/2 (1997): 177-192. Souriau, A. (2010). "Paisaje". En Diccionario Akal de Estética. Etienne Souriau comp. Madrid. Akal.

Souriau, E. (2010). Diccionario Akal de Estética. Madrid. Akal.

Strauss, L. (1971). Arte, lenguaje, etnografía. México. Siglo XXI.

Tatarkiewicz, W. (2001). Historia de seis ideas: arte, belleza, forma, creatividad, mimesis, experiencia estética. (6ta Ed). Madrid. Tecnos.

\begin{abstract}
The landscape represented during various stages during the production of the Salasaca tapestry is a sample of the processes of aesthetic transculturation that took place within the mentioned town from the 1960s. Through several field visits, it was possible to analyze the life stories of the weavers and artisans of this indigenous group. Based on this information collected, in a process of participant observation, it was possible to create a photographic archive, which articulated with the theoretical revision, gave way to the construction of the plot on which the analysis is based. Salasaca iconography is the link between the material's culture and intangible culture of this town, in which the influence of the plastic arts and design transformed the graphic representation schemes that previously hosted cultural signifiers.
\end{abstract}

Keywords: Transculturation - art - crafts - design - landscape - Salasaca

Resumo: A paisagem retratada em vários estágios durante a produção de Salasaca tapeçaria é um exemplo de processos estéticos transculturais que dão ao interior da aldeia mencionado a partir da década de 1960. Através de várias visitas de campo, foi possível analisar as histórias de vida dos tecelões e artesãos deste grupo indígena. Com base nessas informações coletadas, em um processo de observação participante, foi possível criar um arquivo fotográfico, que articulado com a revisão teórica, deu lugar à construção do enredo em que se baseia a análise. A iconografia de Salasaca é o elo entre a cultura material e imaterial desta cidade, na qual a influência das artes plásticas e do design transformou os esquemas de representação gráfica que anteriormente hospedavam os significantes culturais.

Palavras chave: Transculturação - arte - artesanato - design - paisagem - Salasaca.

[Las traducciones de los abstracts fueron supervisadas por el autor de cada artículo] 